\title{
Study on the model of optimal refugee movement
}

\author{
Yinan Yang \\ School of North China Electric Power University, Hebei 071000, China; \\ 754869937@qq.com
}

Keywords: European refugee crisis, Network Maximum Flow algorithm, Refugee migration.

\begin{abstract}
We set up a refugee migration model based on the improved Network Maximum Flow algorithm. The model depends not only on factors affecting refugee migration movements we have determined, but also the attractiveness of the way countries of the selected route and the restriction of the land and ocean environment to refugees. According to the model, we predict in 2016 the flow of refugees is about 163 million.
\end{abstract}

\section{Introduction}

We investigated the background of the formation of the European refugee crisis. In recent years, the wars led by the US, European countries actively involved in West Asia and North Africa as well as other factors, resulted in the unrest situation in West Asia, North Africa with tribal, ethnic and religious internal conflicts, thereby generating a large number of international refugees across the borderlines. With the geopolitical relations of approaching to Europe, a growing number of refugees in West Asia and Africa came through the Mediterranean, overland South-Eastern Europe and inroad into Europe. Since 2014, tens of thousands of West African refugees have been continuing to enter European countries, so the refugee problem gradually into the view of European governments and mainstream society.

\section{The basic analysis of the model's purpose}

Refugees departed from the Middle East and Africa, then arrived in EU. Before, we have already taken into account personal factors, safety of route, transportation types factors, route selection, countries' resources capacity. In this model, we need to assess the number of refugees, as well as the rate and point of entry necessary to accommodate their movement. During the migration process, our team conduct improvements in the maximum flow algorithm of the network graph theory.

1) Pose the assumptions

(a) Assume that the cities with the opening entrances in a country are projected as many nodes, and these nodes are linked to the same virtual node. The virtual node represents the country;

(b) Assume that a fixed mortality exists in the path through the waters and land.

(c) Assume that six routes eventually reach the different countries.

(d) Assume that the demand of the necessary living resources per capita are same.

2) Establish the Network Model

In light of the main departure cities, way cities and arrival cities during refugees' movements, as well as the routes' environment, we draw the network diagram of six routes. Among them, we design the cities as the nodes, and the migration route of refugees as the arcs of the network diagram. These arcs indicate the direction of movement of refugees and the capacity of the route. 


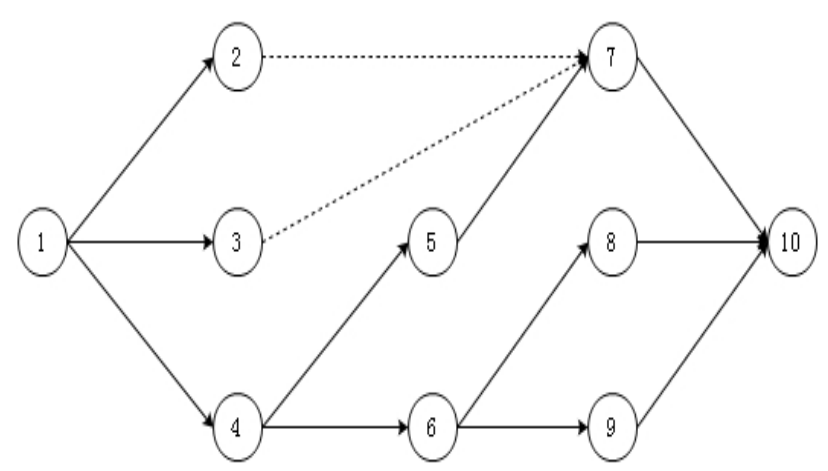

(1)Middle East - western Mediterranean - Greece

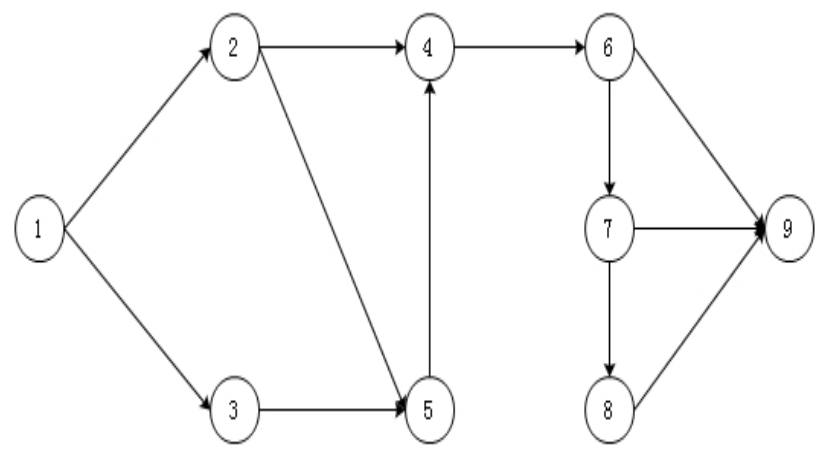

(3)Middle East - Eastern Mediterranean - Greece

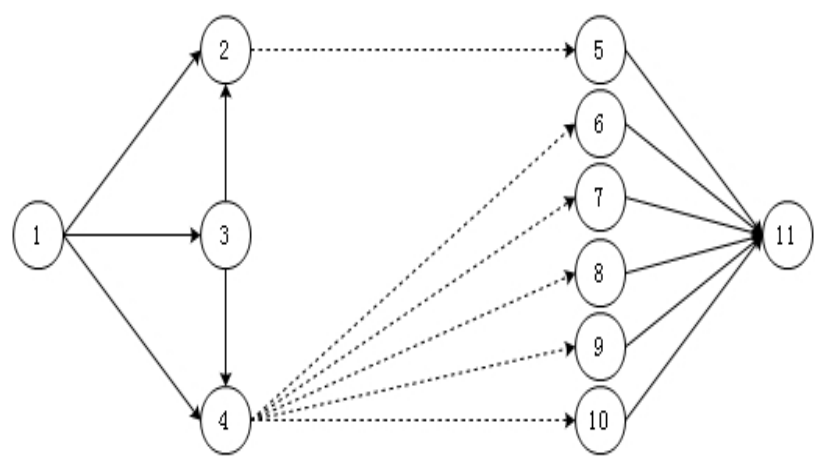

(5)Middle East - Eastern Borders - Greece

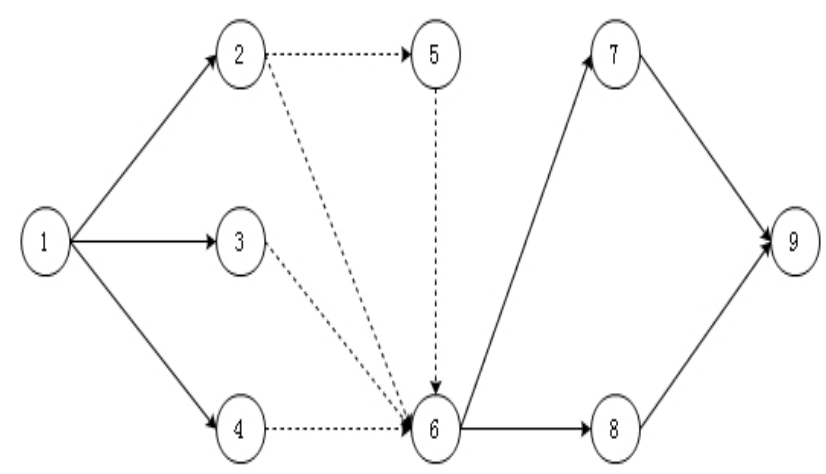

(2)Middle East - Central Mediterranean - Greece

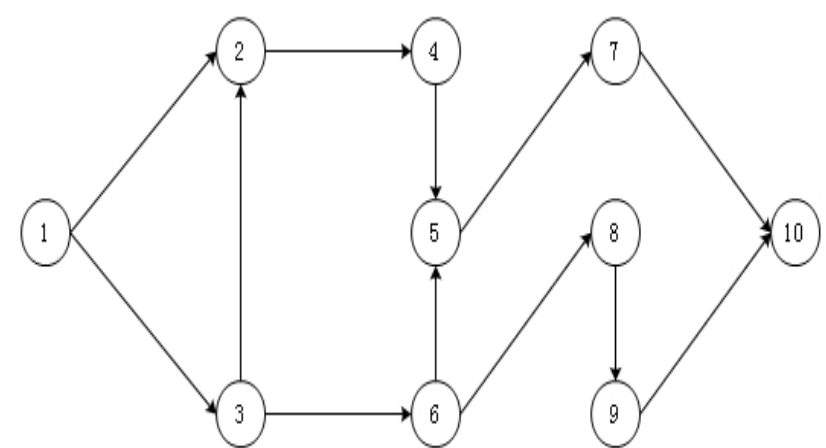

(4) Middle East - West Balkans - Greece

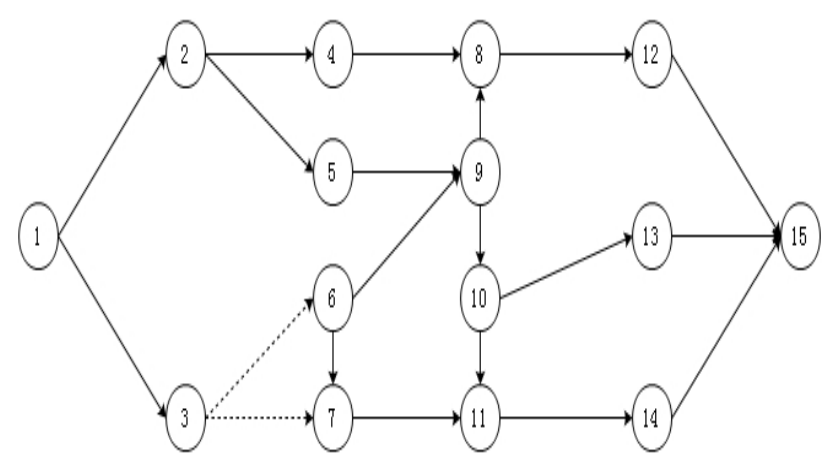

(6) Middle East - Albania - Greece

3) Build a Resistance Model

The weight of each arc of the network represents refugees carrying capacity, the number of accommodating refugees is affected by road environment and a series of factors. When calculating the carrying capacity, we improve it as the resistance of passing the path, namely, a reduction of the amount.

(a) Build a model of resistance of the ocean

When the refugees leave from the Middle East or Africa to Europe countries they will be affected by the terrestrial environment. Indicated by the Frontex's data, each year about 3500 people died in the land during the migration process. In the light of the number of terrestrial mortality, migration, and the incidence of the land traffic accidents, we formulate a safety factor of land. Refugee migration routes show that the way countries' political, economic and social environment and religious beliefs have a certain appeal to refugees, our team formulated a attraction model to show the attraction of the way countries to refugees. We use the environment capacity model to measure a country's degree of resource surplus, which determines whether the country can meet the basic needs of refugees. These two models are likely to make the migration of refugees to abandon the original plan and stay in the way country.

$$
L_{f}=\eta \times N+\sum_{i=1}^{m} \frac{\beta_{i} k_{i} s_{i}}{s_{0}}
$$




$$
\mathrm{k}=1-\frac{s_{0} N}{S}
$$

Where :

$L_{f}$ - The resistance of the land

$\eta$ - The safety factor of the land

$\mathrm{N}$ - The total number of the departure refugees

$\beta$ - The attraction factor of the way country

$\mathrm{k}$ - The environmental capacity factor

$\mathrm{s}_{0}$ - The amount of the necessary living resources per capita

(b) Build a model of the resistance of ocean

UN reported that to the end of 2015, more than 264,500 refugees crossed the Mediterranean, about 104,000 arrived in Italy, and another 160,000 entered Greece, but there are more than 2,000 refugees died on the way. With the same as the resistance of land model , taking into account the physical health and age structure of refugees, legal degree of the vessels which they ride, we develop a resistance model in sea. The equation is represented as follows:

$$
s_{f}=\sum_{j=1}^{b} c_{\tilde{j}} \times N_{j}
$$

Where:

$S_{f}$ - The resistance of the sea

$C_{j}$ - The safety factor of the land

(c) Build a model to estimate arrivals

We can conclude from the analysis of the above models: because the numbers of the opening entrances in destinations are restricted by the amount of resources, refugees can not all enter the destination country. Based on the network maximum flow, the final model of the refugee population who arrive at destinations are shown:

$$
f_{m}=\left[\left(1-\eta_{m}\right) N_{0}-\sum_{i=1}^{\varpi} \frac{\beta_{i} k_{i} S_{i}}{s_{0}}-\sum_{j=1}^{b} C_{j} N_{j}\right]^{\frac{L_{m}}{L_{m 0}}}
$$

\section{The analysis of data and the test of the model}

Taking network diagram (1) for example, we substitute the Frontex's data into our land and oceans resistance model, then we the capacity of each arc. The network diagram with weight:

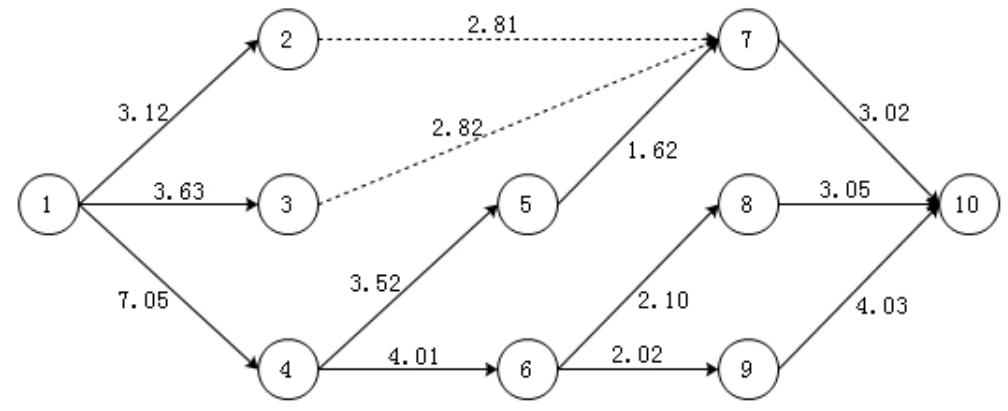

Through MATLAB's Maximum Network Toolbox, we calculate that the maximum flow is from (1) to (10) and the network flow is 8.03 (unit: thousands). The data show that in 2015, from Algeria and Morocco by sea via the Mediterranean Sea west line to Spain, France or Italy, the number of refugee is around 0.7 million people. This shows that our model is reliable. If the path's environment changes, what we need is to calculate the value of resistance on the path. 


\section{Summary}

1) Strengths

We introduce the land and ocean resistance model, and get the calculation formula of the arc capacity. This model can calculate the holding capacity of each route in a relatively accurate way. Combined with the Network maximum flow, we calculate the flow of refugees.

2) Weakness

(a) Many migration routes' effects should be regarded as a more sophisticated network to study. Considering the lacking of conditions and the time for us is limited, we don't make further study in this aspect.

(b) Our model doesn't consider the effects of the factor that refugees' religious beliefs may influence the selection of routes and the destination country.

\section{References}

[1] Hans-Jürgen Zimmermann: Fuzzy Set Theory and its Applications(2001-11).

[2] Eurostat on http://ec.europa.eu/eurosta

[3] The UN Refugee Agency on http://www.unhcr.org/cgi-bin/texis/vtx/home

[4] Frontex on http://frontex.europa.eu/

[5] International Organization for Migration, from: http://www.iom.int/ 